\title{
Hubungan antara OMSK dengan Gangguan Pendengaran di Poliklinik THT RSUD dr. Slamet Garut
}

\author{
Indra Maulana ${ }^{1}$, Iwan Shalahuddin ${ }^{2}$
}

\begin{abstract}
Abstrak
Kejadian OMSK hampir selalu dimulai dengan otitis media berulang pada anak, jarang dimulai setelah dewasa. Faktor infeksi biasanya berasal dari nasofaring, mencapai telinga tengah melalui tuba Eustachiu. Gangguan pendengaran tergantung dari derajat kerusakan tulang-tulang pendengaran. Biasanya di jumpai tuli konduktif namun dapat pula bersifat campuran. Prevalensi OMSK secara umum adalah 3,8\%. Disamping itu pasien OMSK merupakan $25 \%$ dari pasien yang berobat di poliklinik THT rumah sakit di Indonesia. Angka kejadian OMSK yang rendah, di negara maju ditemukan pada pemeriksaan berkala, pada anak sekolah yang dilakukan oleh School Health Service di Inggris Raya sebesar 0,9\%, tetapi prevalensi OMSK yang tinggi juga masih ditemukan pada ras tertentu di negara maju, seperti Native American Apache 8,2\%, Indian Kanada 6\%, dan Aborigin Australia 25\%. Tujuan peneilitian untuk mengetahui hubungan jenis OMSK dengan gangguan pendengaran di Poli Klinik THT RSU dr. Slamet Garut. Desain penelitian yang digunakan adalah analitik korelasi dengan pendekatan cross sectional dengan populasi seluruh pasien yang berkunjunga ke poli THT dengan sampel sebanyak 46 responden. Hasil penelitian menunjukan adanya hubungan yang kuat antara OMSK dengan gangguan pendengaran denga nilai uji statistik didapatkan 5,6 yang berarti nilai hitung lebih besar dari nilai tabel $(3,841)$ dengan menggunakan nilai alpa 0,05. Rekomendasi yang dapat diberikan bahwa penderita OMSK yang disertai dengan keluhan gangguan pendengaran sebaiknya segera memeriksaan kondisinya ke dokter untuk mendapatkan penanganan lebih lanjut, mengingat keluhan gangguan pendengaran menunjukkan tanda bahaya yang diakibatkan oleh penyebaran infeksi ke telinga dalam.
\end{abstract}

Kata Kunci : Gangguan Pendengaran, OMSK, THT

\section{Abstract}

The occurrence of CSOM almost always begins with recurrent otitis media in children, rarely starting after adulthood. Infection factors usually originate from the nasopharynx, reaching the middle ear through the Eustachian tube. Hearing loss depends on the degree of damage to the hearing bones. Conductive deafness is usually found but can also be mixed. The prevalence of CSOM in general is 3.8\%. Besides that CSOM patients constitute $25 \%$ of patients treated at the hospital ENT polyclinic in Indonesia. The low incidence of CSOM, in developed countries, is found in periodic examinations, in school children conducted by the School Health Service in the United Kingdom by 0.9\%, but the high prevalence of CSOM is still found in certain races in developed countries, such as Native American Apache 8.2\%, Canadian Indians 6\%, and Australian Aborigines 25\%. The aim of the study was to determine the relationship between the type of CSOM and hearing loss in the Polytechnic Clinic of RSU Dr. Slamet Garut. The research design used was analytic correlation with cross sectional approach with a population of all patients who visited the ENT poly with a sample of 46 respondents. The results showed that there was a strong relationship between CSOs and hearing loss with statistical test scores obtained at 5.6, which means that the calculated value is greater than the table value (3.841) using an alpha value of 0.05. Recommendations that can be given that people with CSOM accompanied by complaints of hearing loss should immediately examine their condition to the doctor to get further treatment, given complaints of hearing loss shows a danger sign caused by the spread of infection to the ear in the night.

Keywords: ENT, hearing loss, OMSK 


\section{PENDAHULUAN}

OMSK adalah stadium dari penyakit telinga tengah dimana terjadi peradangan kronis dari telinga tengah dan mastoid dan membran timpani tidak intak (perforasi) dan ditemukan sekret (otorea), purulen yang hilang timbul. Istilah kronik digunakan apabila penyakit ini hilang timbul atau menetap selama 2 bulan atau lebih. (Djaafar, 2005).

Prevalensi OMSK pada beberapa negara antara lain disebabkan, kondisi sosial, ekonomi, suku, tempat tinggal yang padat, higiene dan nutrisi yang jelek. Kebanyakan melaporkan prevalensi OMSK pada anak termasuk anak yang mempunyai kolesteatom, tetapi tidak mempunyai data yang tepat, apalagi insiden OMSK saja, tidak ada data yang tersedia. Otitis media kronis merupakan penyakit THT yang paling banyak di negara sedang berkembang. Di negara maju seperti Inggris sekitar $0,9 \%$ dan di Israel hanya $0,0039 \%$. Di negara berkembang dan negara maju prevalensi OMSK berkisar antara 1-46\%, dengan prevalensi tertinggi terjadi pada populasi di Eskimo (12-46\%), sedangkan prevalensi terendah terdapat pada populasi di Amerika dan Inggeris kurang dari 1\% (Lasminingrum L, 2004).

Berdasarkan hasil survei epidemiologi yang dilakukan di tujuh propinsi di Indonesia tahun 1994-1996, didapati bahwa prevalensi OMSK secara umum adalah 3,8\%. Disamping itu pasien OMSK merupakan 25\% dari pasien yang berobat di poliklinik THT rumah sakit di Indonesia. Angka kejadian OMSK yang rendah, di negara maju ditemukan pada pemeriksaan berkala, pada anak sekolah yang dilakukan School Health Service di Inggris Raya sebesar 0,9\%, tetapi prevalensi OMSK yang tinggi juga masih ditemukan pada ras tertentu di negara maju, seperti Native American Apache $8,2 \%$, Indian Kanada 6\%, dan Aborigin Australia 25\%. (Djaafar, 2005)

Penyakit ini merupakan salah satu penyakit infeksi kronis bidang THT di Indonesia yang masih sering menimbulkan ketulian dan kematian. (Djaafar, 2005) Menurut data survei kesehatan nasional indera penglihatan dan pendengaran, prevalensi OMSK di Indonesia antara 3,0$5,20 \%$. Kira-kira kurang lebih 6,6 juta penduduk Indonesia menderita OMSK (Depkes RI, 2005)

Data poli klinik THT RSUP $\mathrm{H}$. Adam Malik Medan tahun 2006 menunjukkan pasien OMSK merupakan 26\% dari seluruh kunjungan pasien (Aboet, 2007), sedangkan pada tahun 2007 dan 2008 sebesar 28 dan 29\%. Survei prevalensi diseluruh dunia, yang walaupun masih bervariasi dalam hal definisi penyakit, metode sampling serta mutu 
metodologi, menunjukkan beban dunia akibat OMSK melibatkan 65-330 juta orang dengan telinga berair, $60 \%$ di antaranya (39-200 juta) menderita kurang pendengaran yang signifikan (Aboet, 2007).

Pasien OMSK yang datang ke RSCM Jakarta (2001) kurang lebih 90\% berasal dari masyarakat sosioekonomi lemah. Namun demikian sebagian besar $( \pm 80 \%)$ dari mereka secara tidak teratur sudah pernah berobat ke dokter umum, dokter THT, atau diobati sendiri berulangulang dengan obat tetes. Sebagian dari pasien ini datang oleh karena ketulian yang sudah mengganggu komunikasi atau sudah disertai tanda komplikasi (Djaafar, 2005). Rambe pada penelitiannya yang dilakukan antara April 2002 - Juli 2002 di RSUP. H. Adam Malik Medan terhadap 94 sampel telinga penderita OMSK, mendapatkan jenis gangguan pendengaran yang terbanyak dijumpai adalah tuli konduktif sebanyak 75 telinga $(79,8 \%)$, tuli campur sebanyak 16 telinga (17\%) dan tuli saraf sebanyak 3 telinga (3,2\%) (Rambe, 2002).

Wisnubroto pada penelitian retrospektif di RS. Soetomo Surabaya antara tahun 1999-2002, dari data rekam medis penderita OMSK yang telah menjalani pembedahan telinga, tercatat hanya ada 475 rekam medis yang dilengkapi hasil audiogram prabedah. Yang mengalami tuli konduktif terdiri dari
$93(19,6 \%)$ kasus OMSK reversibel, 140 (29,5\%) kasus OMSK benigna dan 115 $(24,2 \%)$ sebagian kasus OMSK maligna. Sisanya $127 \quad(26,7 \%)$ kasus OMSK maligna sudah mengalami tuli perseptif berat sampai total (Wisnubroto, 2003).De Azevedo et al pada penelitiannya terhadap 115 penderita OMSK dengan dan tanpa kolesteatoma, mendapatkan 78 penderita OMSK dengan kolesteatoma dan sebanyak 15 penderita (13\%) mengalami tuli sensorineural (De Azevedo et al, 2007).

Data subdivisi otologi THT-KL RSCM Jakarta antara Januari 2002Desember 2006, dari 212 penderita OMSK tipe maligna yang menjalani pembedahan telinga, didapatkan 53 penderita (25\%) mengalami tuli sensorineural (Restuti, 2007). Evaluasi audiometri penting untuk menentukan fungsi konduktif dan fungsi koklea. Dengan menggunakan audiometri nada murni hantaran udara dan tulang, besar kerusakan tulang pendengaran dapat diperkirakan, dan manfaat dari operasi rekonstruksi telinga tengah terhadap perbaikan pendengaran dapat ditentukan (Ballenger, 1997; Djaafar, 2000).

Penyebab penyakit telinga kronis yang efektif harus didasarkan pada faktorfaktor penyebab dan pada stadium penyakitnya. Bila didiagnosis kolesteatom, maka mutlak harus dilakukan operasi, tetapi obat dapat digunakan mengontrol infeksi sebelum operasi. Prinsip pengobatan tergantung dari jenis penyakit 
dan luasnya infeksi, di mana pengobatan dapat dibagi atas Konservatif dan Operasi.

Berdasarkan latar belakang yang telah diuraikan di atas, peneliti tertarik untuk mengetahui hubungan antara OMSK dengan gangguan pendengaran di Poli Klinik THT RSU dr. Slamet Garut.

\section{METODE PENELITIAN}

Desain penelitian yang digunakan adalah analitik korelasi dengan pendekatan cross sectional. Arikunto (2010) menyatakan bahwa penelitian korelasi bertujuan untuk mengetahui sejauh mana hubungan antara variabel yang diteliti. Rancangan cross sectional merupakan rancangan penelitian yang pengukuran atau pengamatanya dilakukan secara simultan pada satu saat atau sekali waktu (Hidayat, 2007). Metode analitik korelasi pada penelitian ini digunakan untuk mengukur hubungan otitis media supuratif kronis (OMSK) dengan gangguan pendengaran di Poli Klinik THT RSU dr Slamet Garut.

Variabel penelitian adalah sesuatu yang digunakan sebagai ciri, sifat, dan ukuran yang dimiliki atau didapatkan oleh satuan penelitian tentang sesuatu konsep pengertian tertentu (Notoatmodjo, 2010). Menurut Sugiyono (2009), jenis variabel penelitian yang sering digunakan yaitu: Variabel bebas (independent variable) adalah variabel yang menjadi sebab atau berubahnya dependent variable. Variabel bebas dalam penelitian yaitu otitis media supuratif kronis (OMSK). Variabel terikat (dependent variable) adalah variabel yang dipengaruhi atau yang menjadi akibat karena adanya variabel bebas, dan variabel ini sering disebut variabel respon. Variabel terikat dalam penelitian adalah gangguan pendengaran.

Populasi dalam penelitian ini adalah seluruh pasien yang berobat di Poli Klinik THT RSU dr. Slamet Garut Tahun 2013. Sampel adalah sebagian atau wakil dari populasi yang di teliti (Arikunto, 2010). Menurut Hidayat (2007), sampel merupakan bagian populasi yang akan diteliti atau sebagian jumlah dari karakteristik yang dimiliki oleh populasi. Pengambilan sampel penelitian adalah secara non probability consecutive sampling yaitu setiap pasien yang memenuhi kriteria penelitian dimasukkan kedalam penelitian sampai kurun waktu tertentu, sehingga jumlah pasien yang diperlukan terpenuhi (Notoatmodjo, 2010).

Kriteria sampel untuk Inklusi adalah Pasien di Poliklinik THT RSU dr. Slamet Garut, usia 12-40 tahun, bersedia ikut penelitian, sama sekali belum pernah operasi timpanomastoidektomi. Kriteria Eksklusi, yaitu pasien tidak bersedia diikutsertakan dalam penelitian, pernah dilakukan operasi timpanomastoidektomi, berumur di bawah 12 tahun, tuli kongenital (sejak lahir), menderita penyakit yang menyebabkan tuli sensorineural, riwayat/ sedang menggunakan obat-obatan bersifat 
ototoksik, riwayat terpapar bising yang lama atau terpapar bunyi sangat keras.

Penentuan jumlah minimal sampel berdasarkan pengamatan pendahuluan dengan menggunakan rumus :

$$
\begin{aligned}
& n=\frac{Z_{\alpha}{ }^{2} \cdot P(1-P)}{d^{2}} \\
& n=\frac{1,96^{2} \cdot 0,86 \cdot 0,14}{0,1^{2}} \\
& n=46,25 m 46
\end{aligned}
$$

Keterangan :

$Z_{\alpha}$ : nilai standar distribusi statistik pada kesalahan tertentu $\alpha$ adalah 5\% $=1,96$

$\mathrm{P}$ : Proporsi gangguan pendengaran pada penderita OMSK $=86 \%$ (Sheahan, Donnelly \& Kane, 2001)

$\mathrm{d}$ : tingkat akurasi nilai estimasi dengan nilai sebenarnya $=10 \%$

Besar sampel yang didapat minimal 47 orang. Dengan demikian, besar sampel minimal adalah 46 pasien di Ruang Poli Klinik THT Rumah Sakit Umum dr. Slamet Garut. Untuk memperoleh penyajian data sebagai hasil yang berarti dan kesimpulan data yang baik diperlukan pengolahan data (Notoatmojo, 2010). Pengolahan dengan menggunakan tahapan sebagai berikut: Coding, Editing, Entry,
Tabulating dan Cleaning. Analisis data dilakukan dengan analisis univariat denga tabel distribusi frekuensi dan analisis bivariat dengan menggunakan Chi-square (CI 95\%) dengan $\mathrm{p}-$ Value $=0,05$.

\section{HASIL DAN PEMBAHASAN}

\section{Hasil Penelitian}

Penelitian tentang hubungan OMSK dengan gangguan pendengaran, dilakukan dengan mengobservasi dan mengisi angket yang telah ditentukan dengan hasil seperti yang dapat dilihat di bawah ini :

Tabel 1. Distribusi Frekuensi OMSK dan

\begin{tabular}{|c|c|c|c|c|c|c|c|}
\hline \multirow[t]{2}{*}{ No } & \multirow[t]{2}{*}{ Kategori } & \multicolumn{2}{|c|}{ OMSK } & \multicolumn{2}{|c|}{$\begin{array}{c}\text { Non } \\
\text { OMSK }\end{array}$} & \multicolumn{2}{|c|}{ Total } \\
\hline & & $\mathbf{F r}$ & $\%$ & $\mathbf{F r}$ & $\%$ & $\mathbf{F r}$ & $\%$ \\
\hline 1 & 12-20 Tahun & 3 & 6,52 & 6 & 13,04 & 9 & 19,56 \\
\hline 2 & 21-30 Tahun & 7 & 15,22 & 6 & 13,04 & 13 & 28,26 \\
\hline 3 & 31-40 Tahun & 13 & 28,26 & 11 & 23,92 & 24 & 52,18 \\
\hline & Total & 23 & 50 & 23 & 50 & 46 & 100 \\
\hline
\end{tabular}
Tidak OMSK Berdasarkan Umur di Poli THT RSU dr. Slamet Garut

Berdasarkan tabel 1 menunjukan bahwa sebagian besar penderita OMSK pada golongan umur 31-40 tahun sebesar presentase $52,17 \%$ dan sebagian kecil terjadi pada golongan usia 12-20 tahun sebanyak $19,56 \%$.

Tabel 2. Distribusi Frekuensi OMSK dan Tidak OMSK Berdasarkan Jenis Kelamin di Poli THT RSU dr. Slamet Garut

\begin{tabular}{clcccccc}
\hline \multirow{2}{*}{ No } & \multirow{2}{*}{ Kategori } & \multicolumn{2}{c}{ OMSK } & \multicolumn{2}{c}{ Non OMSK } & \multicolumn{2}{c}{ Total } \\
\cline { 3 - 8 } & & Fr & $\mathbf{\%}$ & $\mathbf{F r}$ & $\mathbf{\%}$ & $\mathbf{F r}$ & \% \\
\hline 1 & Laki-laki & 12 & 26,09 & 8 & 17,39 & 20 & 43,48 \\
2 & Perempuan & 11 & 23,91 & 15 & 32,61 & 26 & 56,52 \\
& Total & $\mathbf{2 3}$ & $\mathbf{5 0}$ & $\mathbf{2 3}$ & $\mathbf{5 0}$ & $\mathbf{4 6}$ & $\mathbf{1 0 0}$ \\
\hline
\end{tabular}

Berdasarkan tabel 2, menunjukan bahwa responden dengan jenis kelamin laki-laki lebih banyak yang manderita OMSK dibanding perempuan sebesar 26,09\%. 
Tabel 3. Distribusi Frekuensi Gangguan Pendengaran Berdasarkan Umur di Poli THT RSU dr. Slamet Garut

\begin{tabular}{clcccccc}
\hline \multirow{2}{*}{ No } & \multirow{2}{*}{ Kategori } & \multicolumn{2}{c}{ Gangguan } & \multicolumn{2}{c}{ Tidak Gangguan } & \multicolumn{2}{c}{ Total } \\
\cline { 3 - 8 } & & Fr & $\mathbf{\%}$ & Fr & \% & Fr & \% \\
\hline 1 & 12-20 Tahun & 6 & 13,04 & 3 & 6,52 & 9 & 19,56 \\
2 & 21-30 Tahun & 4 & 8,70 & 9 & 19,56 & 13 & 28,26 \\
3 & 31-40 Tahun & 13 & 28,26 & 11 & 23,92 & 24 & 52,18 \\
& Total & $\mathbf{2 3}$ & $\mathbf{5 0}$ & $\mathbf{2 3}$ & $\mathbf{5 0}$ & $\mathbf{4 6}$ & $\mathbf{1 0 0}$ \\
\hline
\end{tabular}

Berdasarkan Tabel 3, menunjukan bahwa responden yang mengalami adanya gangguan pendengaran sebagian besar pada kelompok usia 31-40 tahun sebesar 28,26\% dan sebagian kecil pada usia 21-30 tahun sebesar 8,70\%.

Tabel 4 Distribusi Frekuensi Gangguan Pendengaran Berdasarkan Jenis Kelamin di Poli THT RSU dr. Slamet Garut

\begin{tabular}{clcccccc}
\hline \multirow{2}{*}{ No } & Kategori & \multicolumn{2}{c}{ Gangguan } & \multicolumn{2}{c}{ Tidak Gangguan } & \multicolumn{2}{c}{ Total } \\
\cline { 3 - 8 } & & Fr & $\mathbf{\%}$ & Fr & \% & Fr & \% \\
\hline 1 & Laki-laki & 9 & 19,56 & 11 & 23,92 & 20 & 43,48 \\
2 & Perempuan & 14 & 30,44 & 12 & 26,08 & 26 & 56,52 \\
& Total & $\mathbf{2 3}$ & $\mathbf{5 0}$ & $\mathbf{2 3}$ & $\mathbf{5 0}$ & $\mathbf{4 6}$ & $\mathbf{1 0 0}$ \\
\hline
\end{tabular}

Berdasarkan tabel 4 menunjukan responden sebagian besar megalami gangguan pendengaran pada jenis kelamin perempuan sebesar 30,44\%.

Tabel 5. Hubungan OMSK dengan Gangguan Pendengaran di Poli THT RSU dr. Slamet Garut

\begin{tabular}{llccc}
\multirow{2}{*}{ Ko Kategori } & Gangguan & Tidak Gangguan & Total \\
\cline { 3 - 5 } & & $\mathbf{F r}$ & $\mathbf{F r}$ & $\mathbf{F r}$ \\
\hline 1 & OMSK & 16 & 7 & 23 \\
2 & Tidak OMSK & 9 & 14 & 23 \\
& Total & $\mathbf{2 5}$ & $\mathbf{2 1}$ & $\mathbf{4 6}$ \\
\hline
\end{tabular}

Berdasar tabel 5 menunjukan responden penderita OMSK dengan gangguan pendengaran sebanyak 16 responden, sedang yang tidak mengalamin gangguan sebanyak 7 responden. Disamping itu yang tidak menderita OMSK tapi mengalami gangguan pendengaran sebanyak 9 orang dan yang tidak mengalami gangguan pendengaran sebanyak 14 orang.

Dengan uji Chi-Square, nilai $\mathrm{X}^{2}$ hitung yang didapat sebesar 5,6. Nilai ini lebih besar dai nilai $\mathrm{X}^{2}$ tabel yang bernilai
3,841 pada taraf signifikan $=0,05$ dengan $d b=1$ serta koefisien kontingensi 0,47. Dengan demikian nilai $X^{2}$ yang didapat dari hasil perhitungan menunjukan adanya korelasi antara OMSK dengan terjadinya gangguan pendengaran.

\section{Pembahasan}

Data-data yang diperoleh dari hasil penelitian yang dilakukan di Poliklinik THT-KL RSUD Dr.Slamet Garut tersaji dalam tabel-tabel yang disajikan pada paparan sebelumnya. Data-data didapatkan dari 46 responden yang terbagi menjadi 
dua kelompok yaitu responden yang menderita OMSK dan tidak menderita OMSK.

Tabel 1 di atas menyajikan distribusi frekuensi sampel OMSK dan tidak OMSK menurut kelompok umur. Penderita yang tercakup dalam penelitian ini yaitu penderita yang berumur 12-40 tahun. Meskipun kelompok umur penderita OMSK ini bervariasi, frekuensi yang terbanyak pada penelitian ini yaitu pada kelompok umur 31-40 tahun yaitu sebanyak 13 orang atau sekitar 28,26\%.

Dari tabel 2 di atas, jumlah penderita OMSK baik yang berjenis kelamin lakilaki maupun perempuan memiliki jumlah yang hampir sama besar yaitu masingmasing berjumlah 11 dan 12 orang atau sekitar $26 \%$. Hal ini sesuai dengan yang diungkapkan oleh Alabbasi et al (2010). berdasarkan hasil penelitian yang ia lakukan, bahwa secara statistik tidak ada perbedaan antara penderita OMSK lakilaki dan perempuan.

Tabel 3 di atas, memberikan informasi bahwa penderita gangguan pendengaran terbanyak pada rentang umur 31-40 tahun. Sedang pada Tabel 4 di atas, menunjukkan bahwa penderita gangguan pendengaran terbanyak yaitu pada penderita dengan jenis kelamin perempuan. Jumlah penderita gangguan pendengaran perempuan hampir mendekati dua kali lipat dari penderita gangguan pendengaran lakilaki.
Menurut Abrol et al (2001), penderita pada dekade keempat. Di samping itu, ia juga mengungkapkan perempuan lebih mudah terserang gangguan pendengaran dibanding laki-laki. Perubahan yang terjadi selama siklus menstruasi, kehamilan, dan menopause dapat menyebabkan perubahan homeostasis cairan labirin karena mereka memiliki pengaruh langsung pada proses enzimatik dan tindakan neurotransmitter. Setiap perubahan dalam metabolisme hormon steroid bertanggung jawab untuk siklus ovarium, menyebabkan komplikasi seperti gangguan vestibular (Schmidt, 2010).

Tabel 5 di atas, menyajikan hubungan antara OMSK dengan terjadinya gangguan pendengaran. Jumlah penderita OMSK yang mengalami gejala gangguan pendengaran yaitu sebesar 16 orang dari 23 orang penderita gangguan pendengaran atau sebesar $69,56 \%$. Berdasarkan hasil penelitian Long et al (2001) 53\% penderita OMSK dengan komplikasi ekstrakranial yaitu otorrhoea disertai dengan gangguan pendengaran. Seperti yang diungkapkan Jose (2004), penderita OMSK harus mengenali tanda bahaya gangguan pendengaran seperti vertigo yang diakibatkan oleh penyebaran infeksi ke telinga dalam. Pasien harus segera berkonsultasi kepada dokter jika gejala ini muncul. 
Tabel 5 di atas merupakan tabel $2 \times 2$ yang digunakan untuk menguji ada tidaknya hubungan antara OMSK dengan terjadinya gangguan pendengaran. Dari tabel ini, analisis perhitungan statistik dengan uji chi kuadrat dilakukan, sehingga mendapatkan hasil $X^{2}$ sebesar 5,6. Nilai ini lebih besar dari $\mathrm{X}^{2}$ tabel yang bernilai 3,841 dengan taraf signifikansi 0,05 dan derajat kebebasan 1, hal ini berarti hipotesa nol (ditolak), sehingga keputusannya hipotesa alternatif di terima yang berarti ada hubungan antara OMSK dengan terjadinya Gangguan Pendengaran.

\section{KESIMPULAN DAN SARAN}

\section{Kesimpulan}

Penelitian yang telah dilakukan di Poliklinik THT dengan jumlah sampel sebanyak 46 orang memberikan simpulan bahwa Penderita gangguan pendengaran terbanyak yaitu pada kelompok umur 3140 tahun. Gangguan pendengaran lebih banyak terjadi pada perempuan daripada laki-laki. Terdapat hubungan yang signifikan antara Otitis Media Supuratif Kronis (OMSK) dengan terjadinya gangguan pendengaran.

\section{Saran}

Peneliti berharap hasil penelitian ini menjadi sumber pengetahuan baik bagi masyarakat kedokteran maupun bagi masyarakat luas. Penderita OMSK disertai dengan keluhan gangguan pendahulu sebaiknya segera memeriksaan kondisinya ke dokter agar mendapat penanganan lebih lanjut, mengingat keluhan gangguan pendengaran menunjukkan tanda bahaya yang diakibatkan penyebaran infeksi ke telinga dalam.

Hasil penelitian ini belum cukup untuk mengetahui lebih lanjut hubungan OMSK dengan terjadinya gangguan pendengaran pada pasien karena terbatasnya waktu dan sarana penelitian. Agar lebih sempurnanya penelitian, peneliti berharap akan adanya penelitian serupa dengan subjek dan jangkauan populasi yang lebih luas. Selain itu, penelitian dengan penggunaan alat ukur yang lebih sensitif dan spesifik, seperti kalorimeter dan uji fistula, juga sebaiknya dilakukan untuk mendapatkan hasil penelitian yang lebih valid.

1, 2 Fakultas Keperawatan Universitas Padjadjaran

\section{DAFTAR PUSTAKA}

Aboet Askaroellah. (2007). Radang Telinga Tengah Menahun. Pidato Pengukuhan Jabatan Guru Besar Tetap dalam Bidang Ilmu Kesehatan Telinga Hidung Tenggorok Bedah Kepala Leher pada Fakultas Kedokteran, diucapkan di hadapan Rapat Terbuka Universitas Sumatera Utara. Medan: Universitas Sumatera Utara, pp:2-10.

Aboet, A. (2007). Radang Telinga Tengah Menahun. Universitas Sumut: Medan

Abrol Raman et al. (2001). Prevalence and Etiology of Vertigo in Adult Rural Population. Indian Journal Of Otolalaryngology and Head and Neck Surgery. 53: 5.

Acuin Jose. (2004). Chronic Suppurative Otitis Media Burden of Illness and Management Options. Geneva: WHO,pp:9-12 
Alabbasi Ahmed M., et al. (2010). Prevalence and Patterns of Chronic Suppurative Otitis Media and Hearing Impairment In Basrah City. J.Med.Med.Sci. 130: 131.

Arikunto, Suharsimi. (2010). Prosedur Penelitian Suatu Pendekatan Praktik. Edisi Revisi. Jakarta: PT Rineka Cipta.

Bashiruddin Jenny, dkk. (2008). Gangguan Keseimbangan dan Kelumpuhan Nervus Fasialis.Dalam: Efiati Arsyad Soepardi dkk Tenggorokan Kepala Leher Edisi Keenam. Jakarta: Balai Penerbit FKUI, pp:94-101.

Christanto, A. et al. (2007). Pendekatan Molekuler (RISA) untuk Membedakan Spesies Bakteri Otitis Media Supuratif Kronik Benigna Aktif. Cermin Dunia Kedokteran No. 155

Depkes Kementerian Kesehatan Republik Indonesia, (2010). Telinga Sehat Pendengaran Baik. Diunduh dari: http://www.depkes.go.id/index.php/b erita/press-release/840-telinga-sehatpendengaran-baik. [Akses

Oktober]

Djaafar Zainul A. dkk. (2008). Kelainan Telinga Tengah. Dalam: Efiati Arsyad Soepardi dkk. Ke-6. Jakarta: Balai Penerbit FKUI, pp:69-74.
Joesoef AA. (2006). Etiologi dan Patofisiologi Vertigo. Dalam: Leksmono P., Moh. Saiful Islam, dkk Dokter Spesialis Saraf Indonesia Surabaya: Airlangga University Press, pp: 209-23.

Lumbantobing S.M. (2007). Vertigo Tujuh Keliling. Jakarta: Balai Penerbit Fakultas Kedokteran Universitas Indonesia, pp:1.

Notoatmodjo, Soekidjo. (2010). Metodologi Penelitian Kesehatan. Edisi Revisi Jakarta : PT Rineka Cipta

Schmidt Paula Michele da Silva et al. (2010). Hearing and Vestibular Complaints During Pregnancy. Braz.j. Otorhinolaryngol. 76: 1-3

Soetirto, Indro, dkk. 2008. Gangguan Pendengaran dan Kelainan Telinga dalam Buku Ajar Ilmu Kesehatan Telinga Hidung Tenggorok Kepala dan Leher edisi keenam. Balai Penerbit FK UI. Jakarta.dalam Buku Ajar Ilmu Kesehatan Telinga Hidung Tenggorok Kepala dan Leher edisi keenam. Balai Penerbit FK UI. Jakarta. 